\title{
EXPERTOS EN FISIOLOGÍA: RESUMEN DE LO QUE DEBES SABER DE LAS HORMONAS TIROIDEAS
}

\section{EXPERTS IN PHYSIOLOGY: SUMMARY ON WHAT YOU NEED TO KNOW ABOUT THYROID HORMONES}

\section{Lam de Calvo, Oris*; Castillero de Santos, Lilibeth*}

*Departamento de Fisiología Humana de la Facultad de Medicina de la Universidad de Panamá. Panamá, Panamá.

Recibido: 2 de octubre del 2020

Aceptado: 22 de febrero del 2021

Lam de Calvo O, Castillero de Santos L. Expertos en Fisiología: Resumen de lo que debes saber de las hormonas tiroideas. Rev méd cient. 2021; Volumen 33(2): página 31-45. DOI: 10.37416/rmc.v33i2.604

\section{RESUMEN}

La glándula tiroides secreta dos hormonas importantes, la tiroxina y triyodotironina. Se conoce ahora, una regulación más selectiva de la síntesis de triyodotironina a partir de la desyodación de tiroxina en los tejidos blanco; esto permite una mayor disponibilidad de hormona en un determinado tejido, de acuerdo con sus necesidades fisiológicas, o lo protege de los niveles exageradamente altos. La glándula tiroides tiene la capacidad de almacenar y autorregular el ingreso de yodo a la misma y de desviar la síntesis hormonal hacia la triyodotironina ante escasa ingesta de yodo. Además de los receptores nucleares, se conocen otros receptores para las hormonas tiroideas, localizados en las mitocondrias y en la superficie de la membrana plasmática, y sus efectos son esenciales en el desarrollo, crecimiento y metabolismo.

Palabras claves: Yodo, Hormonas Tiroideas, Metabolismo, Hormona Liberadora de Tirotropina, Hipertiroidismo, Hipotiroidismo, Receptores de T3, Receptores de T4

\section{ABSTRACT}

The thyroid gland secretes two important hormones, thyroxine and triiodothyronine. It is now known that a more selective regulation of the synthesis of triiodothyronine from the deiodination of thyroxine in target tissues exist. This allows a greater availability of hormone in certain tissues, according to physiological needs, and conversely protects it from excessively high levels of said hormone. The thyroid gland has the ability to store and selfregulate the entry of iodine into it and to divert hormonal synthesis towards triiodothyronine in the face of low iodine intake. In addition to nuclear receptors, other receptors for thyroid hormones are known and are located in the mitochondria and on the surface of the plasma membrane; their effects are essential in development, growth and metabolism.

Keywords: lodine, Thyroid Hormones, Metabolism, Thyrotropin-Releasing Hormone, Hyperthyroidism, Hypothyroidism, T3 Receptors and T4 Receptors.

Expertos en fisiología: resumen de lo que debes saber de las hormonas tiroideas. Artículo de revision by Lam de Calvo, Oris and Castillero de Santos, Lilibeth is licensed under a Creative Commons Attribution-NonCommercialNoDerivs 4.0 Unported License. 


\section{INTRODUCCIÓN}

Las hormonas tiroideas, tiroxina $\left(T_{4}\right) \quad y$ triyodotironina $\left(T_{3}\right)$, se sintetizan en la glándula tiroides. Ellas son las únicas hormonas que requieren de un oligoelemento, el yodo, para su síntesis. Su secreción está controlada por la tirotropina (TSH), la cual es secretada por la adenohipófisis. Las hormonas tiroideas actúan sobre múltiples tejidos y son esenciales para el desarrollo normal, el crecimiento y el metabolismo. La ausencia o secreción excesiva de estas produce alteraciones importantes en el metabolismo. ${ }^{1}$

A continuación, revisaremos la síntesis, secreción, transporte, metabolismo, mecanismo de acción, regulación de la secreción, efectos fisiológicos y alteraciones en la secreción de las hormonas tiroideas.

\section{BIOSÍNTESIS DE HORMONAS TIROIDES}

La glándula tiroides está formada por una agrupación de folículos, siendo estos la unidad funcional de la misma. (Ver Figura 1).

Cada folículo tiene una apariencia más o menos esférica con una cavidad rellena de una sustancia coloide y se encuentra rodeada por una capa de células epiteliales cuboides llamadas tirocitos o células foliculares. El primer paso en la síntesis de hormonas tiroideas es el atrapamiento del yoduro por la célula folicular gracias a la acción del cotransportador sodio/yoduro (NIS). El yoduro entra posteriormente al lumen folicular, a través de un transportador de aniones llamado Pendrina. (Ver Figura 2).
Figura 1. Estructura de la glándula tiroides.

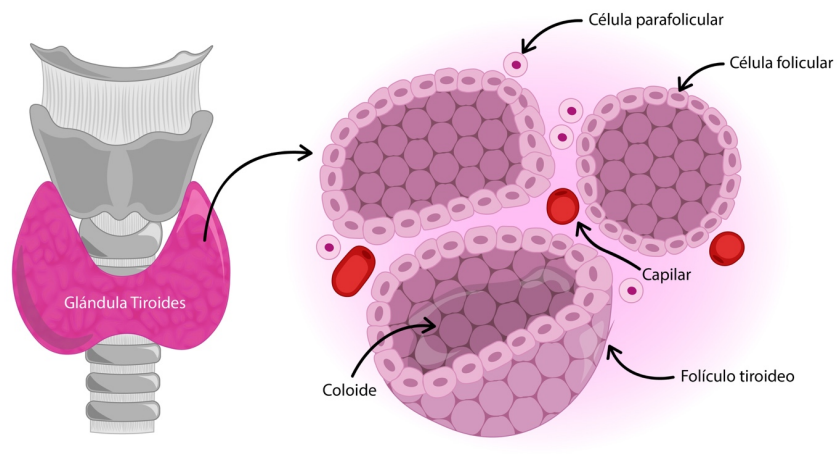

La glándula tiroides está situada delante de la tráquea. Los dos lóbulos están unidos por un puente, el istmo, el cual en ocasiones tiene el lóbulo piramidal.

La glándula está conformada por numerosos folículos. Cada folículo tiene una cavidad central rellena de una sustancia coloide y está rodeada por una monocapa de células epiteliales cuboides Ilamadas tirocitos.

Fuente: Elaboración propia. Diseñada por Gabriela Russo y Juan Buitrago.

El segundo paso en la síntesis de las hormonas tiroideas es la síntesis y empaquetamiento de una glucoproteína de cien radicales tirosilos denominada tiroglobulina. Las vesículas con tiroglobulina se funden con la membrana apical y liberan su contenido al coloide; las vesículas acarrean la enzima yoduro peroxidasa tiroidea (TPO) en su superficie interna. Cuando la vesícula se funde con la membrana apical, esta enzima queda en la membrana y cataliza la oxidación del yoduro $\left(\mathrm{I}^{-}\right)$a yodo (Iㅇ) o a yodonio $\left(\mathrm{I}^{+}\right)$. Además de la enzima, es necesario un sistema generador de $\mathrm{H}_{2} \mathrm{O}_{2}$ para elevar el yoduro al estado de oxidación necesario. El sistema generador de $\mathrm{H}_{2} \mathrm{O}_{2}$ consiste en dos enzimas conocidas como dual oxidasas 1 y 2 (DUOX 1 y 2 ), también se denominan oxidasas tiroideas (ThOX 1 y 2) dependientes de $\mathrm{Ca}^{++}$y NADPH. Este corresponde al tercer paso de la síntesis. ${ }^{2,3}$ 
Figura 2. Síntesis de hormonas tiroideas

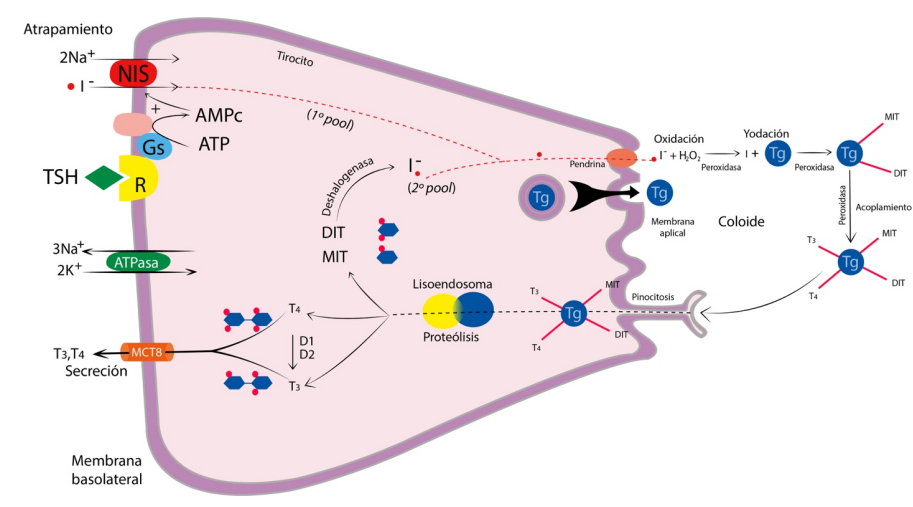

Atrapamiento de yoduro, síntesis de tiroglobulina, oxidación del yoduro, yodación de la tiroglobulina, acoplamiento, pinocitosis, proteólisis y secreción hacia la sangre de $T_{3}$ y $T_{4}$.

Fuente: Elaboración propia. Diseñada por Gabriela Russo y Juan Buitrago.

En el cuarto paso, el yodo oxidado se incorpora en la tiroglobulina durante un proceso denominado yodación de la tiroglobulina y es catalizado por la enzima yodasa. Los radicales tirosilos yodados con un solo yodo se denominan mono yodo tirosina (MIT). Los radicales tirosilos doblemente yodados se denominan di yodo tirosina (DIT). Menos de veinte radicales tirosilos de cada molécula de tiroglobulina sufren yodación.

El quinto paso es la reacción de acoplamiento en la que dos residuos de DIT se acoplan entre sí formando la $T_{4}$. También ocurre el acoplamiento entre un residuo de MIT y otro de DIT y forman la $T_{3}$. Esta reacción de acoplamiento es catalizada por la enzima TPO mencionada previamente y requiere del sistema generador del $\mathrm{H}_{2} \mathrm{O}_{2}$. El $75 \%$ de las tirosinas yodadas no se acoplan y permanecen como MIT y DIT.

Finalmente, para la secreción de $T_{4}$ y $T_{3}$, el tirocito incorpora gotas del coloide por pinocitosis, los lisosomas se funden con las vesículas de pinocitosis, las proteasas digieren las moléculas de tiroglobulina y liberan $\mathrm{T}_{4}$ y $\mathrm{T}_{3}$; estas moléculas son secretadas a la circulación por difusión o por la acción de los transportadores de membrana de monocarboxilato 8 (MCT8). Cada molécula de tiroglobulina origina siete moléculas de MIT, cinco de DIT y dos de $\mathrm{T}_{4}$; por cada tres moléculas de tiroglobulina se origina una molécula de $T_{3}$. Los MIT y DIT no se secretan a la circulación y pierden el yodo por la acción de la enzima desyodasa de yodotirosina microsómica en el citoplasma del tirocito, también denominada yodo tirosina deshalogenasa 1 (DEHAL-1). Este yodo es reutilizado para la síntesis de hormonas tiroideas, proceso conocido como el reciclaje del yodo. ${ }^{2}$

\section{SECRECIÓN Y TRANSPORTE EN LA SANGRE DE LAS HORMONAS TIROIDEAS}

La glándula tiroides secreta a diario $80 \mu \mathrm{g}$ de $\mathrm{T}_{4}, 4 \mu \mathrm{g}$ de $T_{3}$ y $2 \mu \mathrm{g}$ de $T_{3}$ reversa, principalmente mediante el transportador MCT8 presente en la membrana basolateral de los tirocitos. En la sangre, el $99.98 \%$ de la $\mathrm{T}_{4}$ y el $99.5 \%$ de la $\mathrm{T}_{3}$ se unen a las proteínas plasmáticas que incluyen, globulina de unión a tiroxina (TBG), transtirretina (TTR), que se conocía en el pasado como TBPA (pre-albúmina ligadora de tiroxina), y a la albúmina. Debido a la gran afinidad a las proteínas plasmáticas, $T_{4}$ y $T_{3}$ se liberan con lentitud a las células de los tejidos. Al entrar a las células blanco, se unen nuevamente a proteínas intracelulares como cristalina $\mu$ (CRYM) y se utilizan con lentitud a lo largo de periodos de días a semanas. ${ }^{2,3}$

En la determinación de las concentraciones séricas de las hormonas tiroideas es importante diferenciar entre las concentraciones totales y la hormona libre. Cuando ocurren aumentos o disminuciones de las proteínas plasmáticas que transportan a las hormonas tiroideas, se presentan aumentos o disminuciones de las concentraciones de las 
hormonas tiroideas totales; sin embargo, las concentraciones de las hormonas libres se mantienen normales gracias al mecanismo de retroalimentación negativa sobre la TSH y a los pacientes se les considera eutiroideos. Por ejemplo, la TBG se puede incrementar en casos de gestación, terapia oral con estrógenos, hepatitis y abuso de heroína, o reducir en casos de uso de esteroides y en el síndrome nefrótico.

\section{METABOLISMO DE LAS HORMONAS TIROIDEAS}

La $T_{4}$ y la $T_{3}$ pueden ser metabolizadas por diferentes vías: desyodación, conjugación, sulfatación, descarboxilación y desaminación. La desyodación es la vía metabólica más importante. Existen tres desyodasas de yodotironinas diferentes: la 5 'desyodasa tipo 1 (D1), la 5'desyodasa tipo 2 (D2) y la 5 desyodasa tipo 3 (D3). (Ver Figura 3).

La desyodación representa, además de una vía de metabolización e inactivación y de ser el último paso de la síntesis de la mayor cantidad de $T_{3}$, un sistema de regulación más individualizado a nivel de los tejidos diana, respondiendo a las necesidades fisiológicas de los mismos..$^{3,4}$

Figura 3. Estructura química y metabolismo por desyodación de las hormonas tiroideas.

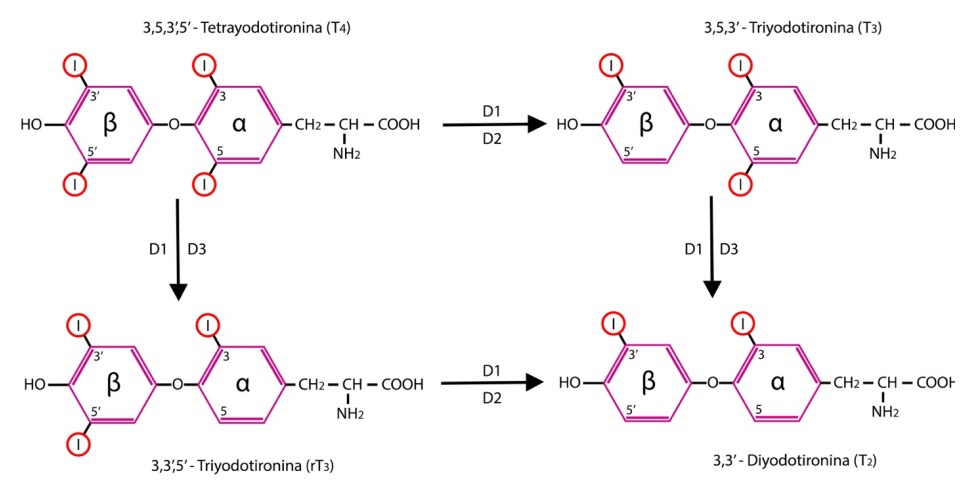

Las hormonas tiroideas están formadas por 2 anillos bencénicos unidos por un puente de oxígeno. Obsérvese que la $T_{4}$ tiene dos átomos de yodo en cada anillo, mientras que la $T_{3}$ tiene sólo un átomo de yodo en el anillo fenólico externo beta y dos átomos de yodo en el anillo interno alfa. Las desyodasas D1, D2 y D3 catalizan la eliminación de átomos de yodo en las posiciones 5 o 5' produciendo la activación o inactivación de las hormonas tiroideas.

Fuente: Elaboración propia. Diseñada por Gabriela Russo y Juan Buitrago.

La D1 se encuentra en el hígado, riñones y tiroides. Su función principal es generar las concentraciones plasmáticas de $T_{3}$, pero también tiene un papel en la recuperación del yoduro de los derivados inactivos para su reutilización en la síntesis de hormonas tiroideas. En el hipertiroidismo, aumenta su actividad en el hígado y riñones; en cambio en el hipotiroidismo, disminuye su actividad en estos tejidos, disminuyendo así la $T_{3}$ circulante y conservando de esta manera la $\mathrm{T}_{4} .^{5}$

La D2 se encuentra en el cerebro, adenohipófisis, tejido graso pardo, piel, glándula tiroides, músculo esquelético, corazón y placenta. Su función principal es la producción de $\mathrm{T}_{3}$ intracelular en los tejidos periféricos específicos. A diferencia de la desyodasa tipo 1 , en el cerebro y piel, tiene una mayor actividad en el hipotiroidismo $y$ menor actividad en el hipertiroidismo. ${ }^{5}$

La D3 se encuentra en el cerebro, piel, hígado, intestinos, placenta e hígado fetal. Su función principal es la de inactivar $\mathrm{T}_{4}$ y $\mathrm{T}_{3}$, protegiendo así a los tejidos de las altas concentraciones de ellas. ${ }^{5,6}$ Esta enzima tiene una mayor actividad en el tejido fetal y tumoral, por lo que se le considera una proteína oncofetal. En casos de hipertiroidismo, presenta mayor actividad en el cerebro y piel; y en casos de hipotiroidismo, menor actividad. 
MECANISMO DE ACCIÓN DE LAS HORMONAS TIROIDEAS

Los diferentes subtipos del receptor de las hormonas tiroideas median las acciones de las hormonas tiroideas en una variedad de compartimentos celulares, incluyendo el núcleo, las mitocondrias y la membrana plasmática.

$\mathrm{T}_{3}$ y $\mathrm{T}_{4}$ tienen baja tasa de difusión a través de la membrana celular, a pesar de ser liposolubles, debido a su tamaño y por ser moléculas sin carga, entran a la célula blanco principalmente a través de transportadores de membrana específicos: transportadores de monocarboxilato (MCT8 y MCT10), y otros con menos especificidad que incluyen a los transportadores de aminoácidos tipo L (LAT1 y LAT2) y los polipéptidos transportadores de aniones orgánicos (OATP). El MCT8 predomina en el cerebro, miocardio, hígado, riñones, glándulas suprarrenales, hipotálamo, adenohipófisis y glándula tiroides; mientras que el MCT10 predomina en el intestino, hígado, riñones, músculo esquelético $\mathrm{y}$ placenta. ${ }^{1,5} \mathrm{El}$ MCT8 transporta $\mathrm{T}_{4}, \mathrm{~T}_{3}$ y $\mathrm{rT}_{3}$; el MCT10, principalmente $T_{3}$; los LAT1 y LAT2, $T_{3}$ y $T_{4}$ con muy poca especificidad y los transportadores OATP, $T_{4}, T_{3}$ $\mathrm{y} \mathrm{rT}_{3}$.

En el año 2004, se encontró la mutación del transportador MCT8 en el Síndrome Allan Herdon Dundley descrito en 1944. En este síndrome ligado al cromosoma $X$, los pacientes presentan retardo psicomotor y resultados paradójicos de la función tiroidea: aumento de $T_{3}$, disminución de $T_{4}$ y TSH normal. Estos pacientes presentan signos de hipotiroidismo en el sistema nervioso; sin embargo, tienen efectos catabólicos en el tejido adiposo y en el músculo esquelético, típicos del hipertiroidismo. ${ }^{3,4}$

La mayor parte de las acciones de las hormonas tiroideas se ejercen a nivel genómico mediante el control de la expresión de genes específicos. La regulación puede ser positiva, por ejemplo, estimulando la síntesis de la hormona de crecimiento (GH) o negativa como en el caso de inhibir la síntesis de TSH y de la hormona liberadora de tirotropina (TRH).

Los receptores nucleares para las hormonas tiroideas (TR) son factores de transcripción nuclear sensibles a hormonas, están unidos a la cromatina y alteran la transcripción de genes específicos. Hay cuatro TR verdaderos que poseen un dominio de unión al ADN y un dominio de unión a T3: TR $\alpha 1-p 46, T R \beta 1, T R \beta 2$ y TRß3. Estos TR presentan 10 veces más afinidad para $\mathrm{T}_{3}$ que para $\mathrm{T}_{4}$. EI TR forma un heterodímero con el receptor del ácido 9-cis-retinoico llamado Receptor Retinoide $X(R X R)$; dicha unión intensifica la unión del receptor tiroideo con el $A D N$, generando mayor actividad biológica. ${ }^{1,3,7}$

Existen diferentes isoformas de TR $\alpha 1$ localizadas en la mitocondria, en la membrana plasmática y el núcleo. Los receptores TR $\alpha 1-p 28$ y TR $\alpha 1-p 43$ se localizan en la membrana interna mitocondrial y en la matriz mitocondrial, respectivamente. El receptor TRa1-p30 se localiza en la membrana plasmática de osteocitos, donde se puede unir la $\mathrm{T}_{3}$ para mediar la señalización. ${ }^{5}$ (Ver Figura 4) 
Figura 4. Mecanismo de acción de las hormonas tiroideas.

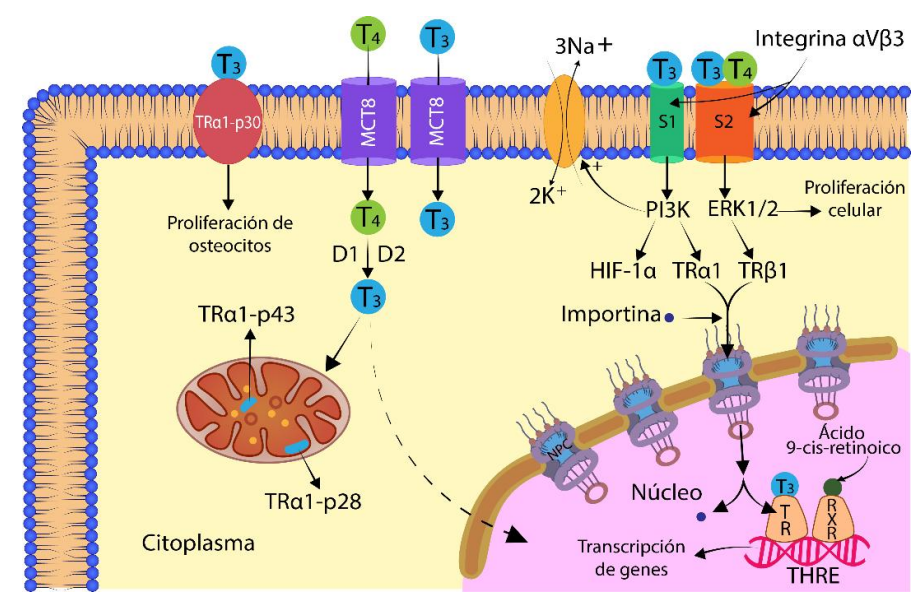

$L a T_{4}$ y $T_{3}$ libres entran a la célula blanco. $L a T_{4}$ se desyoda y convierte en $T_{3}$. El receptor nuclear de hormona tiroidea (TR) forma heterodímero con el receptor del ácido retinoico (RXR). El complejo TR-RXR se encuentra unido al $A D N$ en el Elemento de Respuesta a Hormonas Tiroideas (THRE). La unión de $T_{3}$ al receptor induce aumento o disminución de la transcripción de genes que rigen la sintesis de proteínas. El receptor de membrana integrina $\alpha V B 3$ interacciona con $T_{4}$ y $T_{3}$ en dos sitios distintos, $S 1$ y S2. En la mitocondria los receptores TR $\alpha 1-p 43$ y TR $\alpha 1-p 28$ regulan su función.

Fuente: Elaboración propia. Diseñada por Gabriela Russo y Juan Buitrago.

Los TR ejercen sus acciones transcripcionales mediante un grupo de proteínas correguladoras. Estas proteínas se han clasificado en correpresoras y coactivadoras, según medien en los efectos de represión o de activación génica de los TR. Entre las proteínas correpresoras se incluyen: el Correpresor Nuclear ( $\mathrm{N}$-cor) y el Mediador de Silenciamiento para Receptor Retinoico y Tiroideo (SMTR); entre las coactivadoras, el Coactivador-1 del Receptor Esteroidal (SCR-1) y la proteína CREB (CBP). Además se han descrito unas proteínas asociadas al TR, como la Proteína Asociada al Receptor Tiroideo (TRAP), que controlan la respuesta génica a las hormonas tiroideas. $^{4}$

Los TR interaccionan con secuencias específicas de los genes regulados, denominados Elementos de Respuesta a Hormonas Tiroideas (THRE). Ver Figura 4. En ausencia de la hormona, generalmente se induce la represión de la expresión génica; mientras que la unión de la hormona al receptor induce desrepresión seguida de la activación de la expresión génica. En ausencia de $T_{3}$, el complejo TR-RXR, unido a los THRE de los genes de los tejidos diana, forman un complejo proteico con correpresores (SMRT y NCor) que se unen a desacetilasas de histonas ( $\operatorname{Sin} 3$, HDAC), manteniendo la cromatina compacta y la transcripción reprimida. Al unirse $T_{3}$, el receptor cambia de conformación, librando los correpresores y formando un complejo coactivador (SRC-1) con proteínas que inducen la acetilación de la cromatina (CBP/p300, pCAF) y así permitir la transcripción génica. ${ }^{8,9}$ A continuación, se forma una cantidad elevada de ARN mensajero de distintos tipos, seguido en unos minutos u horas de la traducción de este ARN mensajero en los ribosomas citoplasmáticos para formar cientos de proteínas intracelulares. Ejemplos de estos genes son: los que codifican las proteínas de la mielina en el sistema nervioso central, las proteínas Spot 11 y Spot 14 que activan las enzimas lipogénicas del hígado, las cadenas pesadas de alfa miosina en el músculo cardiaco y esquelético y la $\mathrm{GH} .{ }^{1}$ Esto explica en gran medida las alteraciones inducidas por el hipotiroidismo, las cuales se deben a la acción represora de los receptores en ausencia de la hormona sobre la expresión de estos genes. En el caso de los genes regulados negativamente por la $T_{3}$, el proceso es inverso ya que estos son estimulados en ausencia de la $T_{3}$ e inhibidos cuando la $T_{3}$ se une al receptor. Como ejemplos de este mecanismo de inhibición por la $T_{3}$, podemos mencionar la 
transcripción para la síntesis de TSH, TRH, la cadena pesada de beta miosina y la fibronectina.

La expresión de los distintos tipos de receptores varía en los diferentes tejidos. En el cerebro, cerebelo, tracto gastrointestinal, músculo cardiaco, músculo esquelético y tejido óseo predomina el TRa1; en cambio, en el hígado y riñón predomina el TRß1; mientras que, en el hipotálamo, adenohipófisis, cóclea y retina prima el receptor TR $\beta 2$. En el corazón la cantidad de TR $\alpha 1$ y TRß1 son similares. El TRß3 se encuentra en los riñones, hígado y pulmones. Un ejemplo de la importancia de esta diferencia en los tipos de receptores en los tejidos se hace evidente en los casos de resistencia a la hormona tiroidea por alteración del receptor TR $\beta$, en donde se puede observar signos clínicos típicos de hipotiroidismo e hipertiroidismo simultáneamente en el mismo paciente, debido a la falta de la retroalimentación negativa en la adenohipófisis por ausencia de TR $\beta$ en ella; esto produce un aumento de $\mathrm{T}_{4}$ y $\mathrm{T}_{3}$ circulante $\mathrm{y}$ esta $T_{3}$ en exceso estimula los receptores TR $\alpha$ en el corazón produciendo taquicardia; en cambio, en el hígado se observa disminución de la lipogénesis por alteración de los TRß en el mismo.

Otro receptor para las hormonas tiroideas es la integrina $\alpha \mathrm{V} \beta 3$ en las membranas celulares, la cual interacciona con $\mathrm{T}_{4}$ y $\mathrm{T}_{3}$ en dos sitios distintos, $\mathrm{S} 1$ y S2, los cuales activan diferentes cascadas de transducción. $T_{3}$ se une al dominio S1 activando a la enzima fosfatidilinositol 3 quinasa (PI3K), mediando el transporte de TR $\alpha 1$ del citoplasma al núcleo y la posterior activación de genes blancos; también induce la expresión de una subunidad del factor de transcripción inducible por hipoxia (HIF-1 $\alpha$ ). Tanto $T_{3}$ como $\mathrm{T}_{4}$ se unen al dominio $\mathrm{S} 2$, pero con mayor afinidad $T_{4}$, promoviendo una vía de señalización de quinasas que involucra MAPK/ERK1/2 (del inglés mitogen activated protein kinase/extracelular signal regulated kinase). ${ }^{10}$ La unión de $\mathrm{T}_{4}$ al dominio S2 resulta en la fosforilación y translocación del receptor TRß1 al núcleo, fosforilación y activación del receptor de estrógeno $E R \alpha$, aumento de la expresión de los genes para TR $\beta 1$ y ER $\alpha$. Las hormonas tiroideas al actuar sobre la integrina $\alpha \mathrm{V} \beta 3$ en la membrana celular del miocardio, por ejemplo, estimulan los transportadores de membrana que incluyen al intercambiador $\mathrm{Na}^{+} \mathrm{H}^{+}$, la ATPasa $\mathrm{Na}^{+} \mathrm{K}^{+}$, los canales lentos de calcio y la calcio ATP asa (SERCA). ${ }^{5,7,8}$

En la mitocondria también se ha identificado la presencia de una isoforma de receptor tiroideo TRa1-p43 en la matriz mitocondrial que es capaz de unirse al elemento de respuesta a hormona tiroidea presente en la región del asa D del ADN mitocondrial, regulando la síntesis de proteínas mitocondriales, jugando un papel importante en la homeostasis de la glucosa y el desarrollo muscular. Otra isoforma, el TRa1-p28, está presente en la membrana interna mitocondrial. $T_{3}$ se une a ambos receptores regulando la función mitocondrial. $5,7,8$

REGULACIÓN DE LA SECRECIÓN DE LAS HORMONAS TIROIDEAS

La regulación de las hormonas tiroideas ocurre a tres niveles: primero, el eje hipotálamo-hipófisis-tiroides regula la concentración de hormonas disponibles para todos los tejidos; segundo, a nivel de los mismos tejidos blanco, la actividad de las desyodasas regula la cantidad de hormona para ese determinado tejido; tercero, la glándula tiroides regula la cantidad de yodo que capta para la síntesis de hormonas.

La TRH es sintetizada en las neuronas del núcleo paraventricular del hipotálamo y es liberada por sus axones a nivel de la eminencia media, luego es transportada por los vasos portales hasta la glándula adenohipófisis donde estimula, en las células 
tirotropas, la síntesis y secreción de TSH. La TSH es liberada hacia la sangre y estimula la síntesis y secreción de $T_{3}$ y $T_{4}$ en la glándula tiroides. La $T_{3}$ y $T_{4}$ inhiben la síntesis y liberación de TRH y de TSH, mecanismo denominado retroalimentación negativa de asa larga. ${ }^{4}$

La $T_{4}$ se convierte en $T_{3}$ por la acción de la D2; la $T_{3}$ es la que se une a su receptor nuclear en el hipotálamo y en las células tirotropas, inhibiendo la síntesis de TRH y TSH respectivamente. Este mecanismo regula las cantidades disponibles de hormonas tiroideas para todos los tejidos. (Ver Figura 5).

Ante una ingestión insuficiente de yodo ocurre una disminución mayor de la producción de $T_{4}$ que de $T_{3}$, debido a la síntesis preferencial de $\mathrm{T}_{3}$. Por lo tanto, el mecanismo de retroalimentación negativa sirve para poner en marcha una respuesta compensadora de la glándula tiroides antes que la disminución afecte a los tejidos. La gran sensibilidad del mecanismo de retroalimentación negativa entre tiroides $y$ adenohipófisis es de gran utilidad clínica ya que en situaciones de insuficiencia de $\mathrm{T}_{4}$, se detecta un aumento considerable de los niveles séricos de TSH, incluso cuando la $T_{3}$ está dentro de límites normales y aún no se padecen los síntomas de hipotiroidismo.
Figura 5. Regulación de la secreción de las hormonas tiroideas por el mecanismo de retroalimentación negativa.

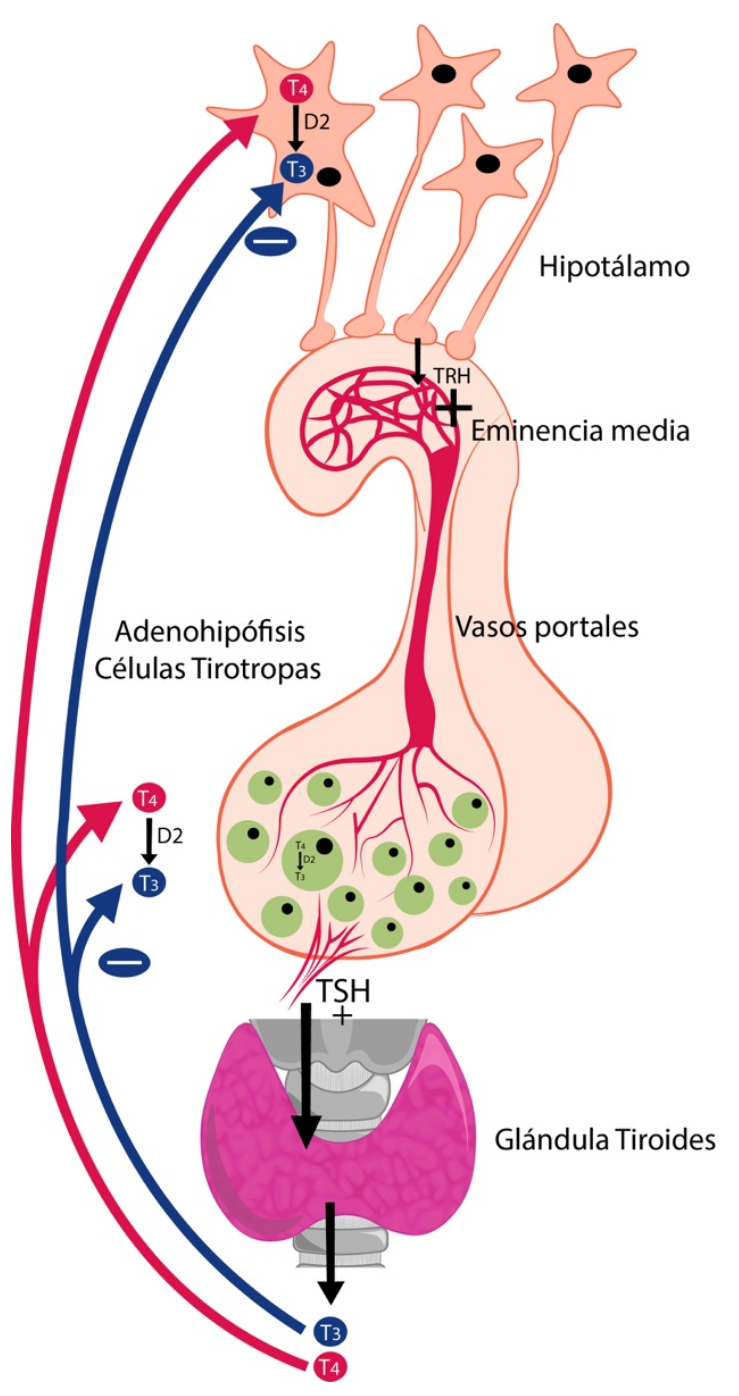

Eje Hipotálamo-Hipófisis-Tiroides. Las hormonas TRH y TSH ejercen un efecto estimulador; la $T_{3}$, un efecto inhibidor. La TRH estimula en la adenohipófisis la secreción de TSH y esta estimula la secreción de $T_{4}$ y $T_{3}$ en la tiroides. $L a T_{4}$, en el hipotálamo y en la adenohipófisis, se desyoda por la acción de la D2 y se convierte en $T_{3}$. La $T_{3}$ se une al receptor nuclear e inhibe las síntesis y secreción de TRH y TSH.

Fuente: Elaboración propia. Diseñada por Gabriela Russo y Juan Buitrago. 
El yodo, principal sustrato para la síntesis de $T_{3}$ y $T_{4}$, es un factor importante en la regulación de la función tiroidea, mecanismo conocido como autorregulación tiroidea. Si por administración aguda de yodo, las concentraciones circulantes se hacen de 10 a 100 veces superiores a las normales, se reduce la respuesta de la tiroides a la TSH y disminuye la actividad del NIS, la síntesis de tiroglobulina y su yodación. Este efecto se conoce como WolffChaikoff. Ante un aumento de la disponibilidad de yodo, el tirocito puede disminuir el transporte del yoduro, evitándose un hipertiroidismo por un exceso de yodo o un hipotiroidismo posterior debido a un bloqueo prolongado de la respuesta a la TSH. Si ocurre un déficit de yodo, se produce un aumento de la respuesta a la TSH y mayor actividad del NIS. ${ }^{2}$ Sin embargo, si la cantidad de yodo ingerida se mantiene escasa por muchos meses aparece bocio debido a la estimulación de la glándula por el exceso de TSH.

\section{EFECTOS DE LAS HORMONAS TIROIDEAS}

En el cuadro 1 se describen los principales efectos fisiológicos de las hormonas tiroideas.

Cuadro 1: Principales Efectos Fisiológicos de las Hormonas Tiroideas $^{2,11,12}$

\section{Efectos fisiológicos}

Metabolismo de Lípidos

Modifican la síntesis, movilización y degradación de los lípidos. Disminuyen la concentración plasmática de colesterol, ya que aumentan los receptores de lipoproteínas de baja densidad (LDL) en las células hepáticas, lo que favorece su depuración del plasma. Aumentan la lipólisis por su efecto a nivel de los receptores $B_{3}$ de los lipocitos.

Metabolismo de Lípidos

Aumento de la lipogénesis por aumento de las enzimas lipogénicas.

Metabolismo de carbohidratos

Metabolismo de proteínas

Termogénesis

\section{Sistema Cardiovascular}

Efecto cronotrópico positivo: aumento de la sensibilidad de los receptores beta a las catecolaminas, lo que aumenta la frecuencia cardiaca.

Efecto inotrópico positivo: aumento de la expresión de la cadena pesada de alfa miosina y el aumento de la sensibilidad de los receptores beta a las catecolaminas, lo que aumenta la contractilidad cardiaca. 
Sistema Cardiovascular

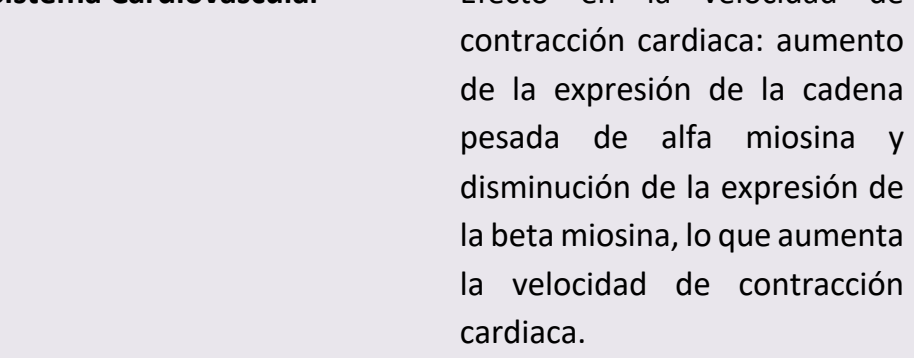

Efecto lusitrópico: aumento de la actividad de SERCA del músculo cardiaco y disminución de fosfolamban, lo que aumenta el secuestro de calcio en la diástole y disminuye el tiempo de relajación.

Presión arterial: aumento de la presión sistólica debido al aumento del gasto cardiaco, producto de los efectos inotrópicos y cronotrópicos positivos.

Disminución de la presión diastólica debido a la vasodilatación de los lechos cutáneos, cardiaco y muscular.

Presión diferencial: aumenta por elevación de la presión sistólica y disminución de la diastólica.

\section{Sistema reproductivo}

Crecimiento
En el hombre favorecen el proceso de espermatogénesis.

En la mujer la maduración del folículo y la ovulación.

Estimulan el crecimiento lineal, el desarrollo y la maduración ósea.
FISIOLOGÍA DE LAS HORMONAS TIROIDEAS EN EL EMBARAZO

Durante el embarazo ocurren cambios normales en la función tiroidea ocasionados por las variaciones hormonales maternas que repercuten en el eje hipotálamo-hipófisis-glándula tiroides, la síntesis y el metabolismo de las hormonas tiroideas. Estos cambios difieren en cada trimestre del embarazo. El aumento de los niveles de estrógeno duplica los niveles circulantes de TBG debido a su mayor producción hepática y su menor degradación periférica, lo que genera que transitoriamente la fracción libre de hormonas tiroideas disminuya y aumenten los niveles de TSH que estimulan la glándula tiroides, dando como resultado un aumento de $T_{4}$ y $T_{3}$ totales con valores normales de $T_{3}$ y $T_{4}$ libres. El aumento de la depuración renal del yodo, la síntesis hormonal aumentada, así como el aumento del catabolismo de las hormonas tiroideas por la desyodasa placentaria aumentan los requerimientos de yodo. La gonadotropina coriónica humana (hCG) y la TSH son glucoproteínas que comparten la misma subunidad alfa y la beta tiene alta homología; la hCG puede estimular al receptor de TSH de las células foliculares y aumentar la producción de hormonas tiroideas, lo que ocasiona, por retroalimentación negativa, una disminución de la TSH adenohipofisiaria. Sin embargo, a medida que el embarazo progresa, los niveles de hCG disminuyen y los de TSH aumentan. En la embarazada, la hiperplasia glandular es común como resultado de la mayor actividad tiroidea. ${ }^{13,14,15}$

\section{EFECTOS DE LAS HORMONAS TIROIDEAS EN EL DESARROLLO DEL SNC FETAL Y POST NATAL}

El desarrollo normal del sistema nervioso central (SNC) depende del adecuado aporte materno hacia el feto de las hormonas tiroideas, del desarrollo 
embrionario normal de la glándula tiroides, su eje hipotálamo hipófisis y la síntesis de hormonas tiroideas por el tejido tiroideo fetal. Estos eventos deben llevarse a cabo durante la gestación de una forma sincrónica y en determinados periodos de tiempo que son críticos para el desarrollo normal del sistema nervioso. ${ }^{16}$

El feto depende de la adecuada concentración de las hormonas tiroideas maternas durante el primer trimestre de la gestación para los procesos de proliferación y migración de los neuroblastos y la D3 evita que altas concentraciones de hormonas tiroideas maternas afecten las neuronas del feto. Al final del primer trimestre, el desarrollo de la glándula tiroides fetal y del eje hipotálamo-hipófisis aumenta la actividad de la D2 que mantiene los adecuados niveles de $\mathrm{T}_{3}$ a nivel del SNC debido a la conversión de $T_{4}$ en $T_{3}$ a nivel de los astrocitos. Durante el segundo y tercer trimestre de gestación, persisten los niveles de $T_{4}$ materna y aumenta la producción de hormona tiroidea fetal, lo que promueve el desarrollo de estructuras cerebrales y los procesos de proliferación glial, mielinización y sinaptogénesis. ${ }^{16,17,18,19}$

En el feto, la $T_{4}$ atraviesa la barrera hematoencefálica (BHE) utilizando exclusivamente el transportador MCT8, ya que la expresión del OATP1C1 en humanos es muy baja. (Ver figura 6).

El transporte de $T_{3}$ a través de la BHE no está claramente establecido durante este periodo. La $\mathrm{T}_{4}$ en los astrocitos es convertida a $\mathrm{T}_{3}$ debido a la presencia de la D2 en ellos. La $T_{3}$ entra a las neuronas utilizando el transportador MCT8 y ejerce sus efectos al activar su receptor nuclear que aparece en el cerebro fetal humano a partir de la décima semana de gestación y aumenta su concentración hacia la semana decimoctava. ${ }^{16,17,18,19}$
Figura 6. Transporte de las hormonas tiroideas al sistema nervioso.

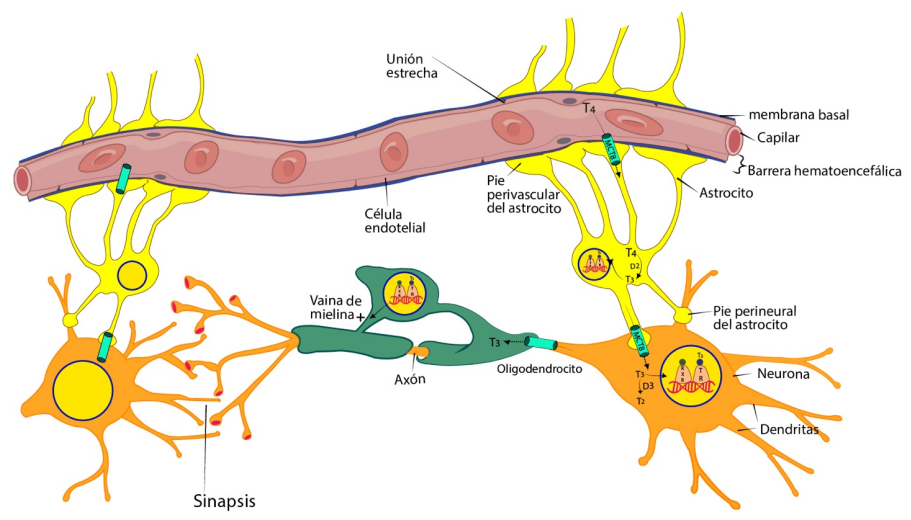

Entrada de $T_{4}$ a través de la barrera hematoencefálica utilizando el transportador MCT8. Conversión de $T_{4}$ a $T_{3}$ en los astrocitos debido a la acción de la D2. Entrada de la $T_{3}$ a la neurona utilizando el transportador MCT8. Mecanismo nuclear de la $T_{3}$ en la neurona que favorece la sinaptogénesis y en el oligodendrocito la mielinización. Metabolismo de la $T_{3}$ a $T_{2}$ en la neurona por la D3.

Fuente: Elaboración propia. Diseñada por Gabriela Russo y Juan Buitrago.

En el período postnatal, el desarrollo del sistema nervioso depende exclusivamente de las hormonas tiroideas sintetizadas en la glándula tiroides del neonato; a nivel cerebral, la $\mathrm{T}_{3}$ tiene un doble origen: la circulante, que en este período se cree que sí puede atravesar la barrera hematoencefálica y la convertida por la D2 en los astrocitos a partir de la $\mathrm{T}_{4}{ }^{16,17,18,19}$

Los dos tipos de desyodasa a nivel cerebral protegen al cerebro de los efectos deletéreos del hipo o hipertiroidismo ya que cuando los niveles de $T_{3}$ son bajos, la D2 aumenta su actividad y los astrocitos convierten la $T_{4}$ circulante en $T_{3}$ activa, mientras que al exponerse a altos niveles de $T_{4}$ y $T_{3}$, la actividad de la D3 de las neuronas se incrementa y las inactivan a $\mathrm{rT}_{3}$ y $\mathrm{T}_{2}$ respectivamente. ${ }^{16,19}$ También es importante destacar el papel protector de la D3 de la 
placenta y el útero durante el embarazo, evitando la alta transferencia de $\mathrm{T}_{4}$ y $\mathrm{T}_{3}$ de la madre hacia el feto.

ALTERACIONES EN EL DESARROLLO DEL SNCDEBIDO A DEFICIENCIAS EN LOS NIVELES DE HORMONAS TIROIDEAS

Existen cuadros clínicos ocasionados por la deficiencia de hormonas tiroideas en los periodos críticos del desarrollo del sistema nervioso. Entre los más comunes encontramos:

- Trastornos por déficit de atención e hiperactividad se observan en los niños nacidos de madres con baja ingesta de yodo durante el embarazo y menor aporte de $\mathrm{T}_{4}{ }^{20}$

- Cretinismo neurológico que se caracteriza por retraso mental, sordomudez y diplejía espástica en miembros inferiores. Se debe a una deficiencia grave en el aporte de yodo (menor de $25 \mu \mathrm{g} /$ día) en la madre y déficit en los niveles de $\mathrm{T}_{4}$ durante la primera mitad de la gestación. ${ }^{21}$

- Cretinismo mixedematoso se ocasiona por una falla de la glándula tiroides fetal o post natal que se debe a ingesta inadecuada de yodo y/o la presencia de bociógenos (tiocianato). Se desarrolla a partir de la segunda mitad de la gestación cuando la glándula tiroides fetal no es capaz de producir niveles adecuados de hormonas tiroideas y el aporte de las hormonas tiroideas maternas no son suficientes para evitar los efectos adversos en el feto. Se caracteriza por retardo mental, pero sin la presencia de síntomas y signos neurológicos. Se presenta con signos de hipotiroidismo, estatura baja, alteraciones craneofaciales y pobre desarrollo del sistema reproductor. ${ }^{21}$

- Hipotiroidismo congénito primario causado por un déficit en la secreción de hormonas tiroideas debido a alteraciones en la glándula tiroides fetal (disgenesia, ectopia, alteraciones enzimáticas) a partir de la segunda mitad de la gestación. El hipotiroidismo congénito primario permanente es su forma más común. En aproximadamente el $85 \%$ es causado por una disgenesia (DT) o anomalía en el desarrollo de la glándula tiroides. La más frecuente es la ectopia (anomalía en la ubicación de la glándula) y la forma más severa de DT es la atireosis o ausencia de tejido tiroideo; esta forma se encuentra presente en aproximadamente $15 \%$ de los niños con hipotiroidismo congénito y es el resultado de un defecto en la determinación/diferenciación de las células endodérmicas pluripotenciales o la apoptosis de las células precursoras tiroideas en etapas tempranas de la organogénesis. El hipotiroidismo congénito puede ser central si la alteración se encuentra a nivel del eje hipotálamo-hipofisiario o periférico si existe una alteración en el transporte o resistencia a la acción hormonal en los tejidos. Ocasiona retraso mental y falta de crecimiento y desarrollo. En el de origen primario, el tratamiento precoz con $\mathrm{T}_{4}$ al recién nacido previene el retraso mental; sin embargo, en algunos casos, permanecen secuelas neurológicas y trastornos del aprendizaje y de la coordinación motora. La determinación de TSH de la sangre del talón del recién nacido es una prueba de detección precoz de este padecimiento y forma parte del tamizaje que se le realiza al recién nacido a término durante sus primeras 48 a 72 horas. Después de las 48 horas de vida, los niveles de TSH producto del estrés y adaptación al nacimiento ya han descendido. Valores de TSH mayores de $20 \mu \mathrm{Ul} / \mathrm{ml}$ en sangre de cordón o $15 \mu \mathrm{Ul} / \mathrm{ml}$ en sangre de talón son sugestivos de hipotiroidismo congénito. ${ }^{21}$

- Síndrome de Allan-Herndon-Dudley (SAHD) que se caracteriza por discapacidad intelectual ligada al cromosoma $X$. Se presenta durante la primera semana de nacimiento y sus manifestaciones clínicas son hipotonía que evoluciona hacia la 
espasticidad (hiperreflexia, clono y Babinski), dificultad para sostener la cabeza, gatear o caminar, profundo retraso cognitivo $(\mathrm{Cl}$ menor de 30) y trastorno del lenguaje. El SAHD es causado por mutaciones en el gen SLC16A2 que codifica para el MCT8 que, como hemos descrito, es importante para transportar la hormona tiroidea hacia las células neuronales. El perfil de hormonas tiroideas asociado a este síndrome se caracteriza por valores elevados de $T_{3}$, valores bajos o normales de $\mathrm{T}_{4} \mathrm{y}$ niveles normales a ligeramente elevados de la TSH. ${ }^{21,22}$

- Síndrome de Resistencia a la acción de las hormonas tiroideas se debe a mutaciones en los genes de los receptores de $T_{3}$ : THR $\alpha$ y THR $\beta$. Se caracteriza por una menor sensibilidad de los tejidos a las hormonas tiroideas. Los pacientes presentan trastornos de la audición, del aprendizaje, menor coeficiente intelectual, déficit de atención e hiperactividad. En el perfil tiroideo es característico el aumento de $\mathrm{T}_{3}$ circulante, disminución de $T_{4}$ y cociente $T_{3} / T_{4}$ elevado. (21) Hoy en día bajo el Síndrome de Resistencia a las hormonas tiroideas se agrupan en tres defectos; el primero a nivel de los transportadores de la membrana celular (receptor MCT8); el segundo, a nivel del metabolismo de las selenocisteínas (desyodasas); y el tercero, a nivel del mecanismo de acción en los receptores nucleares.

ALTERACIONES EN LA SECRECIÓN DE LAS HORMONAS TIROIDEAS

\section{HIPERTIROIDISMO}

La causa más común de hipertiroidismo es la Enfermedad de Graves, en la cual los pacientes desarrollan autoanticuerpos contra el receptor de la TSH, lo que ocasiona que las células foliculares de la glándula tiroides se estimulen y produzcan cantidades excesivas de $\mathrm{T}_{3}$ y $\mathrm{T}_{4}$ y retroalimentación negativa disminuye la TSH.

Las manifestaciones clínicas de la enfermedad guardan correlación directa con efectos exagerados de las respuestas fisiológicas de la $T_{3}$ y $T_{4}$. Los pacientes presentan un incremento de la tasa metabólica asociada a pérdida de peso, sudoración, intolerancia al calor, debilidad muscular (por exceso de proteólisis), dificultad para concentrarse y cambios en el crecimiento del cabello y la textura de la piel. El paciente se queja de irritabilidad, nerviosismo, labilidad emocional e incluso pueden presentar psicosis. El gasto cardiaco aumenta como resultado del aumento de la frecuencia cardiaca, la contractilidad y la disminución de la resistencia periférica total. La presión sistólica se eleva, la diastólica desciende, por lo que la presión de pulso o diferencial aumenta. Desde el punto de vista metabólico, se incrementa la gluconeogénesis hepática, la lipólisis y los adipocitos tienen una mayor capacidad de respuesta a las catecolaminas. Los niveles de IGF-I en el suero se incrementan, lo que aumenta la actividad de los osteoblastos, osteoclastos; por ende, hay desbalance en el recambio óseo y se produce una pérdida ósea acelerada. En las mujeres se presenta oligomenorrea y disminución de la fecundidad; mientras que, en el hombre produce disfunción eréctil y disminución de la movilidad de los espermatozoides, lo que ocasiona también disminución en la fecundidad. El 25 a 50\% de los pacientes con Enfermedad de Graves puede desarrollar una oftalmopatía con proptosis ocular (exoftalmos) debido al aumento de volumen de los músculos extraoculares, el tejido conectivo y adiposo retroorbitario debido al proceso inflamatorio. En la enfermedad avanzada, se puede engrosar la piel pretibial y parecer una cáscara de naranja (mixedema pretibial o dermopatía tirotóxica) 
producto de la estimulación de fibroblastos por citocinas linfocitarias. ${ }^{2,11,12}$

\section{HIPOTIROIDISMO}

El hipotiroidismo es una de las enfermedades endocrinas más comunes que afecta mayoritariamente a las mujeres. Las causas pueden ser deficiencia de yodo o una enfermedad autoinmune que se conoce como Tiroiditis de Hashimoto, en la cual los autoanticuerpos que se producen lesionan a las células foliculares, los microsomas y los receptores de TSH. Hoy en día se conoce que se pueden producir anticuerpos contra la tiroglobulina (Tg Ab), contra el receptor de TSH y contra la peroxidasa tiroidea (TPO Ab). A diferencia de la Enfermedad de Graves, los autoanticuerpos no son estimuladores, sino inhibidores de la función tiroidea normal. Los niveles de $\mathrm{T}_{3}$ y $\mathrm{T}_{4}$ están disminuidos y los de TSH elevados al disminuir la retroalimentación negativa sobre la adenohipófisis y el hipotálamo. Los elevados niveles de TSH ocasionan un aumento difuso del tamaño de la glándula, por lo que el paciente también presenta bocio. 2,11,12,23

Las manifestaciones clínicas de los pacientes con hipotiroidismo son la piel fría y seca por la presencia de proteínas en complejo con polisacáridos, ácido condroitín sulfúrico y ácido hialurónico que promueven la retención de sodio y agua y ocasionan un edema no depresible de la piel, lo que se conoce con el nombre de mixedema. La cara del paciente está hinchada y tiene rasgos burdos. La acumulación de mucopolisacáridos en la laringe da lugar a ronquera. El cabello es quebradizo y no tiene brillo y se presentan áreas de pérdida de cabello en la piel del cuero cabelludo y las cejas. Otras manifestaciones clínicas del paciente son bradicardia, gasto cardiaco bajo, hipotermia, disminución de la tasa metabólica y aumento de peso. Los reflejos profundos están lentos con una fase prolongada de relajación..$^{2,11,12,24}$ Desde el punto de vista metabólico, aumentan los niveles de colesterol y triglicéridos, hay menor actividad de la lipasa de lipoproteína y menor formación de receptores hepáticos de LDL. En las mujeres, se presenta amenorrea y galactorrea; en los varones, esterilidad y ginecomastia ocasionada por la disminución de las gonadotropinas que produce la hiperprolactinemia (el aumento de TRH estimula la liberación de prolactina por la adenohipófisis). ${ }^{2,11,12,23}$

\section{BOCIO ENDÉMICO}

Los factores que predisponen este tipo de bocio son, entre otros, pertenecer al sexo femenino, ser mayor de 40 años, no tener una ingesta adecuada de yodo, residir en un área endémica y tener antecedentes familiares de bocio. En estos pacientes se presenta bocio (agrandamiento de la glándula tiroides) debido a que la deficiencia en la síntesis de las hormonas tiroideas ocasiona una menor retroalimentación sobre el hipotálamo y la adenohipófisis, lo que aumenta los niveles séricos de TSH. La TSH estimula la glándula, produciendo un aumento de tamaño de esta sin aumentar los niveles de hormona circulante debido a la carencia del yodo. ${ }^{2,23}$

\section{CONCLUSIONES}

Las hormonas tiroideas ejercen sus efectos fisiológicos al actuar sobre receptores en la membrana celular, en la mitocondria y en el núcleo. Entran a la célula blanco principalmente por transportadores de membrana. En el núcleo, las hormonas se unen a los receptores unidos a los genes diana para influir en el crecimiento, metabolismo, termogénesis y en la función de los sistemas cardiovascular, reproductor, nervioso y digestivo. 
En condiciones normales, la regulación de las hormonas tiroideas ocurre a varios niveles: en el eje hipotálamo-hipófisis-tiroides, en la misma glándula tiroides y en los tejidos blancos por la actividad de las desyodasas permitiendo mantener un aporte adecuado de las hormonas al sistema más sensible, el sistema nervioso. La deficiencia o exceso de estas hormonas, los defectos de sus transportadores o a nivel de los receptores producen alteraciones que son muy críticas en la vida intrauterina, los primeros años de vida, la adolescencia y la etapa adulta.

\section{AGRADECIMIENTOS}

Los autores agradecen a la ingeniera Gabriela Russo y al licenciado Juan Buitrago por el diseño de las imágenes.

\section{BIBLIOGRAFÍA}

1. Sinha R, Yen P, Cellular Action of Thyroid Hormone Endotext www.endotext.org. June 20, 2018. Disponible en https://www.ncbi.nlm.nih.gov/books/NBK285568/

2. Tresguerres JA. (Ed) Fisiología Humana. Cuarta Edición. Editorial McGraw-Hill, pp 929-938. 2010.

3. Mendoza A, Hollenberg. A. New insights into thyroid hormone action. Pharmacology \& Therapeutics Vol 173:135145.2017

4. Skah S, Uchuya J, Sirakov M, Plateroti M. The thyroid hormone nuclear receptors and the $\mathrm{Wnt} / \beta$-catenin pathway: An intriguing liaison. Developmental Biology. Volume 422, Issue 2:71-82. 2017.

5. Cyril S, Anyetei A, Roggero V, Allison L. Thyroid hormone receptor localization in target tissues. Journal Endocrinol 237 (1)R19-R34. 2018.

6. Schroeder A, Privalsky M. Thyroid hormones, T3 and T4 in the brain. Frontiers in Endocrinology, Vol 5 Article 40. Review. 2014.

7. Litwack G. (Ed). Thyroid hormone. Vitamins and Hormones, First Edition Vol 106, Elsevier Inc, 2018. Capítulo 1, páginas 117.

8. Cheng S, Leonard J, Davis P. Molecular aspects of thyroid hormone actions. Endocr Rev. 31(2):139-170. 2010.

9. Vella K, Hollenberg A. The actions of thyroid hormone signaling in the nucleus. Molecular and Cellular Endocrinology Vol 458:127-135. 2017.

10. Roggero V, Zhang J, Parente L, Doshi Y, Dziedzic R, Allison L. Nuclear import of the thyroid hormone receptor $\alpha 1$ is mediated by importin 7 , importin $\beta 1$, and adaptor importin a1. Molecular and Cellular Endocrinology. Vol 419:185-197. 2016.
11. Boron W, Boulpaeb E. Medical Physiology, Third Edition, Elsevier Inc, pp 1006-1017. 2017.

12. Koeppen B, Stanton B. Berne \& Levy Physiology, Seventh Edition, Elsevier, pp 753-765. 2018

13. Córdoba N., García H., Builes C. Cambios de la función tiroidea en el embarazo: bases para la interpretación de las pruebas tiroideas. latreia, Vol. 26 (2): 185-196. 2013.

14. Pérez J. Pruebas de Función tiroideas en el embarazo. Revista médica de Costa Rica y Centroamérica, LXXI (617) 733-736. 2015.

15. American Thyroid Association [Internet]. La Enfermedad de la Tiroides y el Embarazo. 2016. Disponible en https://www.thyroid.org/

16. Patel J., Landers K., Li H., Mortimer R H and Richard K. Thyroid hormones and fetal neurological development. Journal of Endocrinology, 209, pp 1-8. 2011.

17. Stenzel D., Huttner W. Role of maternal thyroid hormones in the developing neocortex and during human evolution. Frontiers in Neuroanatomy, Vol 7, Article 19. Review. 2013.

18. García-García C. Fisiología tiroidea. Med Int Méx 32(5):569575. 2016

19. Morte B, Bernal J. Thyroid hormone action: astrocyte-neuron communication. Frontiers in Endocrinology Vol 5 Article 82. Review. 2014.

20. Ibañez Toda L., Marcos Salas MV. Actualización en Patología tiroidea. En: AEPap (ed), Curso de Actualización Pediatría 2017. Madrid: Lúa Ediciones 3.0. pp 161-174. 2017.

21. Bernal J. Hormonas tiroideas y Desarrollo Cerebral. Rev Esp Endocrinol Pediatr, Volumen 5. Suplemento (2): 5 a 8. 2014.

22. Ahmed RG. Hypothyroidism and brain developmental players. Thyroid Research. 8:2 Review. 2015.

23. Kasper D., Hauser S., Jameson L., Fauci A., Longo D., Loscalzo J. Harrison, Principios de Medicina Interna. Editorial McGrawHill, 19ª Edición, pp 2283-2308. 2016. 